\title{
EFEKTIFTAS BUBUK DAUN JERUK PURUT (CITRUS HYSTRIX) DAN DAUN SALAM (SYZYGIUM POL YANTHUM) SEBAGAI ZAT PENOLAK ALAMI KECOA AMERIKA (PERIPLANETA AMERICANA) HAMSIR AHMAD ${ }^{1}$, EKA ULFIANI ${ }^{2}$ \\ ${ }^{1.2}$ Poltekkes Kemenkes Makassar ulfiani37@gmail.com
}

\begin{abstract}
Cockroaches are the insects that produce much harm to humans. In addition there is no savory, cockroaches are also a vector of several diseases. American cockroaches are the most common cockroaches found in Indonesian settlements. Efforts to control cockroaches with synthetic insecticides are less safe to use because of the chemicals used to repel cockroaches can also poison humans. Solutions that can be done is to use a natural base repellent substances from plants, such as bay leaves and lime leaves. This study aims to determine the effectiveness of bay leaves and orange leaves as a natural repellent substance for adult American cockroaches. Each treatment was done with 3 repetitions. This study aims to determine the effectiveness of bay leaves and orange leaves as a natural repellent substance for adult American cockroaches. Each treatment was done with 3 repetitions. The type of research used is pure experiment (true experiment). Popuplasi in this study American Cockroach (Periplaneta americana) as much as 260 tail. The results showed that the powdered lime leaf powder was more effective when compared to the bay leaf powder because it was able to dissipate effectively at 60 minutes with a dose of $20 \mathrm{gr}$ averaged 10 of the total samples, while the bay leaf powder was able to dissipate effectively in minutes 60 with a dose of 20 grams average number of cockroaches being displaced up to 9 tails. The conclusions obtained with the same dose and the same time the leaf powder of kaffir lime is more effective when compared with bay leaf powder. It is recommended that the government consider using natural insecticides in vector control.

Keywords: American Cockroaches, Citrus Leaf Purut, Leaf Salam
\end{abstract}

\section{ABSTRAK}

Kecoa merupakan serangga yang banyak menimbulkan kerugian bagi manusia. Selain menimbulkan bau tidak sedap, kecoa juga merupakan vektor beberapa penyakit. Kecoa amerika adalah kecoa yang paling sering ditemukan di pemukiman penduduk. Usaha pengendalian kecoa dengan insektisida sintetik kurang aman untuk digunakan karena zat kimia yang digunakan untuk mengusir kecoa juga dapat meracuni manusia. Solusi yang dapat dilakukan yaitu menggunakan zat penolak berbahan baku alami dari tumbuh-tumbuhan, seperti daun salam dan daun jeruk purut. Penelitian ini bertujuan untuk mengetahui efektifitas daun jeruk dan daun salam sebagai zat penolak alami bagi kecoa amerika dewasa. Masing-masing perlakuan dilakukan dengan 3 kali pengulangan. Jenis penelitian yang digunakan adalah eksperimen murni (true eksperiment). Popuplasi dalam penelitian ini Kecoak Amerika (Periplaneta americana) sebanyak 260 ekor. Hasil penelitian menunnjukkan bahwa bubuk daun jeruk purut lebih efektif jika dibandingkan dengan bubuk daun salam karna mampu mengusir dengan efektif pada menit ke 60 dengan dosis 20 gr rata-rata mencapai 10 dari jumlah sampel seluruhnya yaitu 10 ekor, sedangkan bubuk daun salam mampu mengusir dengan efektif pada menit ke 60 dengan dosis $20 \mathrm{gr}$ rata-rata jumlah kecoak yang terusir hingga 9 ekor. Kesimpulan yang didapatkan dengan dosis yang sama dan waktu yang sama bubuk daun jeruk purut lebih efektif jika dibandingkan dengan bubuk daun salam. Disarankan agar pemerintah mempertimbangkan untuk menggunakan insektisida alami dalam pengendalian vektor.

Kata Kunci : Kecoak Amerika, Daun Jeruk Purut, Daun Salam.

\section{PENDAHULUAN}

Kecoa merupakan salah satu hama pemukiman yang dapat berperan sebagai vektor penyakit yang paling umum ditemukan di tempat tinggal di seluruh dunia. Kecoa dianggap sebagai pengganggu kesehatan karena kedekatannya dengan manusia dan umumnya berkembang biak mencari makan di daerah yang kotor, seperti tempat sampah, saluran pembuangan dan septictank. Makanan kecoa dari makanan yang masih dimakan manusia sampai dengan kotoran manusia.

Berdasarkan data yang dikumpulkan melalui Profil Kesehatan di Indonesia pada tahun 2016 tercatat jumlah kasus tuberkulosis sebanyak 298.128 kasus (100\% dari perkiraan jumlah kasus) dan jumlah kasus diare sebanyak 6.897.463 kasus $(100 \%$ dari perkiraan jumlah kasus).
Sedangkan di Sulawesi Selatan diperoleh jumlah kasus Tuberkulosis sebanyak 12.972 kasus dan jumlah kasus diare sebanyak 230.048 kasus.

Pengendalian vektor adalah semua kegiatan atau tindakan yang ditujukan untuk menurunkan populasi vektor serendah mungkin sehingga keberadaannya tidak lagi beresiko untuk terjadinya penularan penyakit tular vektor dapat dicegah menurut Peraturan Menteri Kesehatan Republik Indonesia Nomor 50 Tahun 2017 tentang Standar Baku Mutu Kesehatan Lingkungan dan Persyaratan Kesehatan Untuk Vektor dan Binatang Pembawa Penyakit Serta pengendaliannya. Salah satu solusi yang dapat dipertimbangkan adalah menggunakan insektisida nabati yang berbentuk sebagai zat penolak (repellent) berbahan baku alami yang diperoleh dari tumbuh-tumbuhan 
Salah satu tanaman yang berpotensi sebagai insektisida adalah daun salam (Syzygium polyanthum). Senyawa eugenol yang terdapat pada daun salam dapat digunakan untuk membasmi kecoa di rumah (Mahardianti, 2014). Daun jeruk purut mengandung minyak atsiri yang didalamnya terdapat senyawa linalool yang dapat digunakan sebagai bahan penolak serangga (Abidatun, 2013). Kedua sediaan tanaman tersebut pada penelitian terdahulu diuji cobakan pada spesies kecoa yang berbeda yaitu Periplaneta americana dan Blatella germanica

Berdasarkan dari uraian-uraian diatas maka penulis tertarik melakukan penelitian mengenai "Efektiftas Bubuk Daun Jeruk Purut (Citrus hystrix) Dan Daun Salam (Syzygium polyanthum) Sebagai Zat Penolak Alami Kecoa Amerika (Periplaneta Americana)".

\section{BAHAN DAN METODE}

\section{Lokasi Penelitian:}

Lokasi penelitian dilakukan di asrama putri Kampus Jurusan Kesehatan Lingkungan Politeknik Kesehatan Makassar dan sampel yang digunakan dalam penelitian ini yaitu dipemukiman kota Makassar.

\section{Desain dan Variabel Penelitian}

Adapun jenis penelitian ini adalah eksperimen murni yaitu untuk mengetahui efektifitas bubuk daun jeruk purut (Citrus hystrix) dan daun salam (Syzygium polyanthum) dalam mengusir kecoa Amerika (Periplaneta Americana).

Adapun variabel penelitian pada penelitian ini terdiri dari 3 variabel. yaitu variabel bebas yang terdiri dari dosis $10 \mathrm{gr}$, $15 \mathrm{gr}$, dan $20 \mathrm{gr}$, variabel terikat yaitu kecoa Amerika (Periplanetta americana). serta variabel pengganggu yaitu suhu dan kelembaban.

\section{Populasi dan Sampel}

Populasi yang digunakan dalam penelitian ini adalah adalah semua spesies kecoa Amerika (Periplanetta Americana).

Sampel dalam penelitian ini adalah 10 ekor kecoa Amerika untuk masing-masing dosis ada 3 macam dan perlakuan sebanyak
$3 x$ replikasi sehingga pada penelitian ini diperlukan jumlah sampel sebanyak 240 ekor kecoa Amerika yang diambil langsung dari pemukiman di kota Makassar.

\section{Pengumpulan data}

Sumber data terdiri dari 2 yaitu data primer yang diperoleh dari hasil pengujian dan data sekunder yang data yang diperoleh dari beberapa referensi baik artikel-artikel, jurnal, penelitian sebelumnya, buku maupun literatur yang lain yang dianggap dapat mendukung teori yang ada serta dianggap memiliki keterkaitan dengan penelitian.

5. Analisa Data (Jika memakai program statistic, tuliskan uji utama apa yang digunakan)

Analisa data dilakukan dengan menggunakan tabel beserta pembahasannya kemudian dianalisa dan diuraikan secara deskriptif sehingga dapat diperoleh suatu kesimpulan yang layak.

\section{HASIL}

\section{Efektifitas Bubuk Daun Jeruk Purut (Citrus hystrix)}

\section{Grafik 1 \\ Hasil Pengamatan Efektifitas Bubuk Daun Jeruk Purut (Citrus hystrix) dengan Dosis $10 \mathrm{gr}, 15 \mathrm{gr}$, dan $20 \mathrm{gr}$ Dalam Mengusir Kecoak (Periplaneta Americana)}

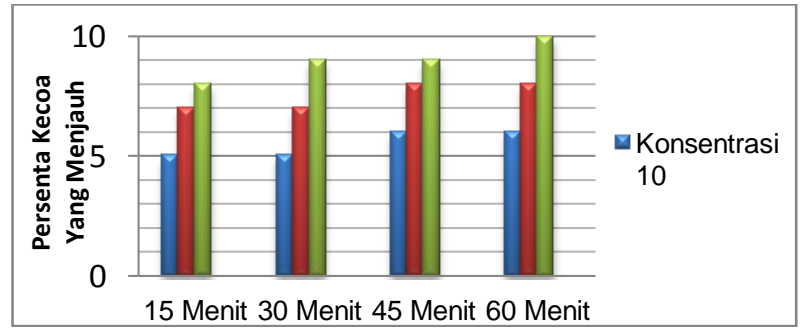

Sumber : Data Primer, 2018 


\section{Efektifitas Bubuk Daun} Grafik 2

Hasil Pengamatan Efektifitas Bubuk Daun Salam (Syzygium polyanthum) dengan Dosis $10 \mathrm{gr}, 15$ gr, dan 20 gr Dalam Mengusir Kecoak

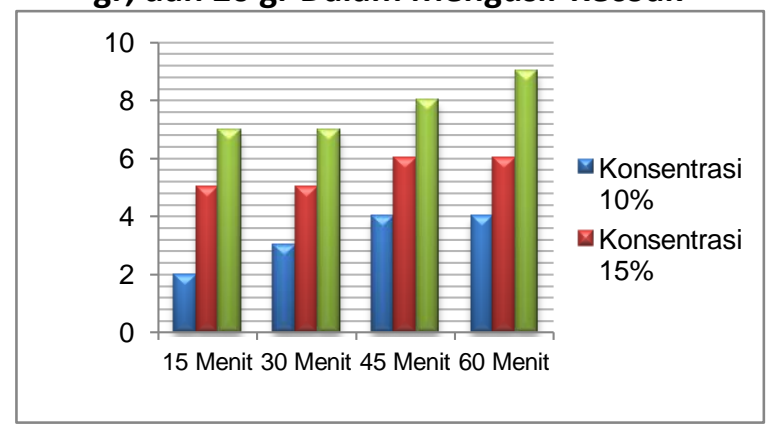

(Periplaneta Americana)

Sumber : Data Primer, 2018

\section{PEMBAHASAN}

1. Efektifitas Bubuk Daun Jeruk Purut (Citrus hystrix) Bubuk Daun Salam (Syzygium polyanthum) dengan Dosis $10 \mathrm{gr}$ Dalam Mengusir Kecoak (Periplaneta Americana)

Berdasarkan Grafik 5.1 tentang efektifitas bubuk daun jeruk purut (Citrus hystrix) dengan dosis $10 \mathrm{gr}$ dalam mengusir kecoak Periplaneta Americana dinyatakan bahwa jumlah kecoak terusir dengan angka paling rendah pada waktu menit ke 15 adalah 4 ekor sedangkan angka terusir yang paling tinggi pada menit ke 60 yaitu 6 ekor kecoak Periplaneta Americana.

Perlakuan penelitian dengan cara menaburkan bubuk daun jeruk purut (Citrus hystrix) dengan dosis $10 \mathrm{gr}$ dinyatakan dapat mengusir kecoak hingga rata-rata 6 ekor dengan persentase $60 \%$ dari jumlah sampel, jika dilihat dalam kontrol tanpa adanya perlakuan memperlihatkan sebuah perbedaan pada menit ke 15 jumlah kecoak yang paling rendah yang terusir hanya rata-rata 1 ekor dengan persentase $10 \%$ dan sedangkan angka yang terusir paling tinggi pada waktu pengujian 60 menit yaitu rata-rata 3 ekor dengan persentase $30 \%$.

Dalam pengamatan sebuah control tanpa adanya perlakuan memperlihatkan kecoak hanya bolak-balik dari wadah $A$ ke wadah $B$ hal ini memperjelas tidak ada pengaruh ketika control dilakukan terhadap kecoak, dibandingkan dengan adanya perlakuan menggunakan larutan daun pandan wangi kecoak yang terusir ke wadah B tidak ada yang kembali dalam waktu 1 jam.

Hal tersebut dikarnakan kandungan yang terdapat dalam daum jeruk purut senyawa citronellal yang terkandung pada sediaan daun jeruk purut berperan sebagai bahan insektisida yang bekerja sebagai antifeedant dan repellent, demikian halnya dengan sesquiterpen diduga dapat mempengaruhi perkembangan serangga (Yuliani, 2005).

Selain bersifat menolak serangga, citronelal dapat bersifat kontak dengan serangga. Hal ini sesuai dengan hasil dari penelitian Khasanah (2015) bahwa kandungan terbesar dalam minyak atsiri daun jeruk purut adalah citronellal yakni $64,15 \%$, selain citronellal $(64,15 \%)$ komponen utama dari minyak atsiri daun jeruk purut (Citrus hystrix) adalah beta-citronellol (10,71\%), trans-caryophillene (5,54\%), dan linalool $(5,31 \%)$.

2. Efektifitas Bubuk Daun Jeruk Purut (Citrus hystrix) dengan Dosis $15 \mathrm{gr}$ Dalam Mengusir Kecoak (Periplaneta Americana)

Berdasarkan Grafik 5.1 tentang efektifitas bubuk daun jeruk purut (Citrus hystrix) dengan dosis $15 \mathrm{gr}$ dalam mengusir kecoak Periplaneta Americana dinyatakan Jumlah kecoak terusir dengan angka paling rendah pada menit ke 15 dan 30 yaitu 7 ekor sedangkan, angka terusir yang paling tinggi pada menit ke 45 dan 60 yaitu 8 ekor kecoak Periplaneta Americana.

Perlakuan penelitian dengan dengan cara menaburkan bubuk daun jeruk purut (Citrus hystrix) dengan dosis $15 \mathrm{gr}$ dinyatakan dapat mengusir kecoak hingga rata-rata 8 ekor dengan persentase $80 \%$ dari 10 total jumlah sampel dan dinyatakan lebih efektif dibanding dengan dosis $10 \mathrm{gr}$, hal tersebut sangat berpengaruh terhadap pemberian dosis atau konsentrasi yang digunakan pada bubuk daun jeruk purut (Citrus hystrix) dapat mempengaruhi system syaraf kecoak yang dijadikan sampel, dan menyebabkan kecoak lari atau terusir menjauh, kecoak tetap pada bak pertama memiliki resistensi terhadap konsentrasi bubuk yang digunakan akan tetapi sudah mampu mengusir kecoak hal ini juga dipengaruhi dari tingginya dosis atau konsentrsi yang digunakan sebelumnya. 
3. Efektifitas Bubuk Daun Jeruk Purut (Citrus hystrix) dengan Dosis $20 \mathrm{gr}$ Dalam Mengusir Kecoak (Periplaneta Americana)

Berdasarkan Grafik 5.1 tentang efektifitas bubuk daun jeruk purut (Citrus hystrix) dengan dosis $20 \mathrm{gr}$ dalam mengusir kecoak Periplaneta Americana dinyatakan bahwa jumlah kecoak terusir dengan angka paling rendah pada waktu menit ke 15 adalah 8 ekor sedangkan, angka terusir yang paling tinggi pada menit ke 60 yaitu 10 ekor kecoak Periplaneta Americana.

Perlakuan penelitian dengan cara menaburkan bubuk daun jeruk purut (Citrus hystrix) dengan dosis $15 \mathrm{gr}$ dinyatakan dapat mengusir kecoak hingga rata-rata 8 ekor dengan persentase $80 \%$ dari 10 total jumlah sampel dan dinyatakan lebih efektif dibanding dengan dosis $15 \mathrm{gr}$.

Hal ini karna kandungan beberapa senyawa aktif yang terdapat pada bubuk daun jeruk purut (Citrus hystrix) serta pemberian dosis atau konsentrasi yang digunakan pada saat perlakuan karna semakin tinggi pemberian dosis atau konsentrasi maka semakin cepat reaksi yang terjadi pada kecoak Periplaneta Americana jadi dapat disimpulkan bahwa dosis $20 \mathrm{gr}$ lebih efektif dari pada dosis $10 \mathrm{gr}$ dan $15 \mathrm{gr}$.

4. Efektifitas Bubuk Daun Salam (Syzygium polyanthum) dengan Dosis $10 \mathrm{gr}$ Dalam Mengusir Kecoak (Periplaneta Americana)

Sedangkan jika dilihat dari Grafik 5.2 tentang efektifitas bubuk daun salam (Syzygium polyanthum) dengan dosis $10 \mathrm{gr}$ dalam mengusir Kecoak Periplaneta Americana dinyatakan bahwa jumlah kecoak terusir dengan angka paling rendah pada menit ke 15 yaitu 2 ekor sedangkan angka terusir yang paling tinggi pada menit ke 60 yaitu 4 ekor kecoak Periplaneta Americana.

Perlakuan penelitian dengan cara menaburkan bubuk daun salam (Syzygium polyanthum) dengan dosis $10 \mathrm{gr}$ dinyatakan dapat mengusir kecoak hingga rata-rata 6 ekor dengan persentase $60 \%$ dari jumlah sampel. Hal ini karna minyak atsiri dalam daun salam mengandung sitral, seskuiterpen, lakton, eugenol dan fenol. Selain itu senyawa yang terkandung dalam daun salam antara lain saponin dan polifenol (Utami, 2013). Senyawa eugenol yang terdapat pada daun salam dapat digunakan untuk membasmi kecoa di rumah (Mahardianti, 2014).
5. Efektifitas Bubuk Daun Salam (Syzygium polyanthum) dengan Dosis $15 \mathrm{gr}$ Dalam Mengusir Kecoak (Periplaneta Americana)

Berdasarkan Grafik 5.2 tentang efektifitas bubuk daun salam (Syzygium polyanthum) dengan dosis $15 \mathrm{gr}$ jumlah kecoak terusir dengan angka paling rendah pada waktu menit ke 15 adalah 5 ekor sedangkan angka terusir yang paling tinggi pada menit ke 45 dan 60 yaitu 6 ekor kecoak c. Dosis $15 \mathrm{gr}$ ini lebih efektif jika dibandingkan degan dosis 10 gr hal ini juga karna dosis yang digunakan.

6. Efektifitas Bubuk Daun Salam (Syzygium polyanthum) dengan Dosis $20 \mathrm{gr}$ Dalam Mengusir Kecoak (Periplaneta Americana)

Berdasarkan Grafik 5.2 dapat dilihat bahwa efektifitas bubuk daun salam dalam mengusir kecoak Periplaneta Americana terjadi pada menit ke 45 yang diamati selama 1 jam. Jika dilihat dari kemampuan dua bubuk ini yang paling efektif mengusir kecoak Periplaneta Americana yaitu bubuk daun jeruk purut karna dapat mengusir dengan efektif pada menit ke 15 sedangkan bubuk daun salam hanya dapat mengusir dengan efektif pada menit ke 45.

Hasil penelitian ini ditunjang oleh pendapat Dalimartha (2000), yaitu salah satu kandungan daun salam adalah minyak atsiri. Aktifitas biologi minyak atsiri terhadap serangga adalah dapat bersifat sebagai repelen (Hartati, 2012). Mekanisme kerja minyak atsiri sebagai repelen yaitu minyak atsiri menguap ke udara sehingga bau yang dihasilkan akan terdeteksi oleh reseptor kimia yang terdapat pada tubuh serangga. Kemudian bau yang tidak disukai serangga tersebut akan diterjemahkan di otak dan diekspresikan dengan menjauhi atau menghindari sumber bau tersebut. Hal tersebut diduga terjadi pada kecoa uji yang diamati, yaitu kecoa menjauhi daun salam karena bau dari minyak atsiri yang tidak disukai oleh kecoaMenurut penelitian sebelumnya dikatakn efektif apabila mampu mengusir kecoak Periplaneta Americana apabila percobaan $>80 \%$.

Penggunaan bubuk daun jeruk purut dan daun salam merupakan penerapan insektisisda nabati sebagai racun kontak yang akan meresap didalam tubuh serangga (insekta), karena kecoak memiliki system pernafasan berupa trakea yang memiliki kontak dengan jaringan luar tubuh kecoak sebagai system pernafasan, sehingga pada 
saat kontak dengan bahan tersebut kecoak akan mengalami kejang-kejang. Karena bahan kimia nabati yang berfungsi sebagai racun kontak dan racun pernafasan terhisap masuk ke system pernafasan, sehingga semakin lama kecoak terpapar maka dampaknya akan semakin tinggi.

Selama proses pelayuan dan pengeringan dimana dalam pengujian hanya dikeringkan dengan angin sampai kering, membrane sel berangsur-angsur akan pecah dan cairan bebas melakukan pentrasi dari satu sel ke sel yang lain sehingga membentuk senyawa yang mudah menguap. Dalam daun jeruk purut tua membrane sel sudah matang dimana tidak terjadi proses penguapan yang besar sehingga kandungan minyak atsiri masih banyak sedangkan hal ini terjadi sebaliknya pada daun jeruk purut (Citrus hystix) muda dimana membrane sel masih terlalu muda sehingga kemampuannya untuk melakukan penetrasi kurang dan kandungan minyak atsirinya masih sedikit sehingga kemampuannya untuk menolak kecoa Amerika kurang efektif dibandingkan dengan daun jeruk purut tua

Pada saat penelitian dilakukan dengan menggunakan hygrometer, didapatkan hasil dimana suhu pada saat pengujian yakni pada replikasi I yaitu $28^{\circ} \mathrm{C}$, replikasi II yaitu $29^{\circ} \mathrm{C}$, dan replikasi III yaitu $30^{\circ} \mathrm{C}$. Jadi suhu rataratanya yaitu $29^{\circ} \mathrm{C}$. Sedangkan kelembabannya yang didapatkan pada saat pengukuran yakni pada replikasi I yaitu sebesar 59\%, repliksi II yaitu 60\%, dan replikasi III yaitu $60 \%$ jadi rata-rata kelembabannya sebesar $60 \%$.

Berdasarkan hasil pengukuran suhu dan kelembaban tersebut, apabila terjadi perbedaan jumlah kecoa yang menghindar karena sediaan repellent antar kelompok uji, maka perbedaan tersebut tidak disebabkan oleh suhu tempat pengujian. Sehingga kecoa yang menjauh pada kotak perlakuan tidak dimungkinkan karena pengaruh suhu tempat penelitian.

Kelembaban merupakan banyaknya uap air yang terkandung dalam udara. Pada umumnya serangga membutuhkan kelembaban stinggi bagi tubuhnya yang dapat diperoleh langsung melalui udara dan tanaman yang mengandung air. Kelembaban pada tempat penelitian harus diperhatikan, agar tidak menjadi pemicu timbulnya faktor lain yang mempengaruhi menghindarnya kecoa selain karena sediaan daun salam dan daun jeruk.

Kelembaban pada tempat penelitian yang tidak sesuai akan menyebabkan kecoa tidak nyaman dan stress, sehingga kecoa yang menghindar tidak dikarenakan sediaan daun salam dan daun jeruk yang diberikan, tetapi tetapi karena faktor kelembaban yang tidak optimal. Kelembaban pada saat penelitian memenuhi standar kelembaban untuk pengujian kecoa sehingga kecoa yang menghindar pada saat perlakuan tidak dimungkinkan karena pengaruh kelembaban pada ruangan pengujian.

Pengendalian kecoa dapat dilakukan dengan beberapa cara seperti pengendalian secara biologis, mekanis, kimiawi, dan dengan cara menjaga sanitasi. Cara kimiawi adalah cara yang sering dilakukan oleh banyak masyarakat seperti dengan penyemprotan atau pengasapan menggunakan insektisida. Namun hal yang dinilai praktis tersebut tanpa disadari dapat meracuni penghuninya karena asap yang mengandung insektisida ini dapat menyebar keseluruh ruangan di dalam rumah. Selain itu residu yang ditinggalkan juga berbahaya bagi manusia . karena dapat menyebabkan mortalitas kecoak sebagai hama pemukiman.

Kecoak dapat hidup dengan memakan apapun. Terlepas dari makanan yang kita makan, mereka juga memakan tanaman mati, hewan, materi feses, lem, sabun, kertas, kulit, dan bahkan helai rambut yang jatuh. Sementara mereka merangkak di malam hari, mereka mencemari makanan terbuka dengan membuang kotoran di atasnya, meninggalkan rambut, kulit mati, dan juga kulit telur yang kosong di dalamnya. Bahaya kecoak lainnya adalah dari air liur mereka. Ketika kecoak makan, mereka memuntahkan air liur dan cairan pencernaan dari mulut mereka sendiri untuk menyuntik makanan Anda dengan kuman atau bakteri yang berada di usus mereka. Bakteri Pseudomonas aeruginosa dapat berkembang biak secara ekstensif dalam usus kecoak. Hal ini dapat menyebabkan beberapa penyakit seperti infeksi saluran kemih, masalah pencernaan, dan sepsis (keracunan darah).

Berdasarkan pemaparan dampak yang ditimbulkan kecoak, maka sangat penting adanya metode pengendalian yang sifatnya efektif dan gampang di aplikasikan serta tidak menimbulkan dampak toksik terhadap 
manusia. Berkembangnya penggunaan pestisida/insektisida sintesis (menggunakan bahan kimia sintetis) yang dinilai praktis oleh para pencinta tanaman untuk mengobati tanamannya yang terserang hama, ternyata membawa dampak negatif bagi lingkungan sekitar bahkan bagi penggunanya sendiri.

Beberapa bahan alami yang secara tradisional diduga dapat digunakan untuk mengusir kecoa adalah timun, daun salam, dan lavender. Daun salam secara turuntemurun telah digunakan sebagai bahan alami penolak kecoa dengan meletakkannya ditempat-tempat yang sering dilalui kecoa (Naria, 2005). Selain itu daun salam juga mengandung senyawa minyak atsiri dan diduga pula dapat digunakan sebagai zat penolak serangga. .

Penelitian terbaru dari Amin (2016) menunjukkan bahwa daun jeruk purut yang dihaluskan dengan cara diblender dapat digunakan sebagai penolak alami bagi kecoa Blatella germanica dewasa. Daun jeruk purut tua lebih efektif dibandingkan daun jeruk purut muda. Menurut Koswara (2009) kandungan dari jeruk purut adalah citronellal $(81,49 \%)$, sitronelol $(8,22 \%), \quad$ geraniol $(0,31 \%)$, linalool $(3,69 \%)$.

Baskoro dkk. (2013) juga menyatakan aroma harum dari minyak atsiri yang dihasilkan melalui ekstraksi kulit jeruk nipis memiliki efek repelen terhadap kecoa amerika dan pada konsentrasi 40\%-50\% memiliki efek yang sebanding dengan napthalene dalam berfungsi menolak kehadiran kecoa amerika. Selain kecoa menurut Sudjari dkk. (2006), ekstak daun salam juga memiliki potensi sebagai repelen nyamuk Culex sp dan pada konsentrasi $7,5 \%$ setara dengan Diethyltoluamide sebagai repelen

Daun jeruk purut mengandung minyak atsiri yang didalamnya terdapat senyawa linalool yang dapat digunakan sebagai bahan penolak serangga (repellent) (Abidatun, 2013). Kedua sediaan tanaman tersebut pada penelitian terdahulu di ujicobakan pada spesies kecoa yang berbeda yaitu Periplaneta americana dan Blatella germanica. Periplaneta americana mempunyai ukuran tubuh yang lebih besar dan kandungan minyak atsiri dari masingmasing sediaan daun yang berbeda. Selain itu daun salam sudah lama dipercaya dapat digunakan untuk mengusir kecoa. Tanamantanaman tersebut adalah tanaman lokal
Indonesia yang kerap dijumpai di masyarakat dan dapat mudah tumbuh sehingga perlu adanya evaluasi perbandingan keefektifan dari kedua sediaan dengan perlakuan yang sama sehingga dapat dimanfaatkan dengan maksimal oleh masyarakat, oleh karena itu perlu dilakukannya penelitian mengenai perbandingan efektivitas daun jeruk purut (Citrus hystrix) dan daun salam (Syzygium polyanthum) sebagai zat penolak alami bagi kecoa Amerika (Periplaneta americana L.) yang bertujuan untuk membuktikan perbedaan efektivitas daun salam (Syzygium polyanthum) dan daun jeruk purut (Citrus hystrix) sebagai zat penolak alami bagi kecoa Amerika (Periplaneta americana L.).

Dapat dikatakan sediaan daun jeruk purut mempunyai daya tolak (repellent) lebih besar yaitu $84 \%$ dibandingkan dengan sediaan daun salam yaitu $80,5 \%$. Berdasarkan uji probit berat sediaan daun jeruk purut yang dapat menolak kecoa sebesar $50 \%$ adalah $1,853 \mathrm{gr}$, berat sediaan yang dapat menolak kecoa sebesar $90 \%$ adalah 8,152 gr. Sediaan daun salam yang dapat menolak kecoa sebesar $50 \%$ adalah 2,445 gr, berat sediaan yang dapat menolak kecoa sebesar 90\% adalah 11,697 gr. Hasil dari uji probit menunjukkan bahwa sediaan jeruk purut dengan berat yang lebih sedikit dapat menolak kecoa dengan jumlah yang sama dengan sediaan daun salam. Takaran sediaan yang terlalu banyak dapat menyebabkan terjadinya resistensi.

Tanaman jeruk purut (Citrus hystrix) merupakan tanaman yang sangat potensial, murah dan mudah didapatkan. Kedua tanaman merupakan tanaman yang dapat digunakan sebagai repellent yang ramah lingkungan karena mudah terurai di alam, sehingga perlu adanya pengembangan dan pengujian lebih lanjut agar dapat memanfaatkan tanaman jeruk purut (Citrus hystrix) secara maksimal sebagai insektisida nabati. Meskipun kemampuan daya tolak daun jeruk purut ini belum seefektif bahan kimia, namun bahan alami ini diharapkan lebih aman untuk digunakan, khususnya pada individu yang peka terhadap insektisida kimia lainnya. 


\section{PENUTUP}

\section{KESIMPULAN}

a. Bubuk daun jeruk purut sebagai zat penolak alami kecoa Amerika (Periplaneta americana L.) mampu mengusir dengan efektif pada dosis 15 gr sedangkan pada bubuk daun salam mampu mengusir pada dosis $20 \mathrm{gr}$.

b. Efektifitas bubuk daun jeruk purut dalam mengusir kecoa Amerika (Periplaneta americana L.) yaitu karna

\section{SARAN}

kandungan citronellal yang bersifat menolak dan kontak serangga, sedangkan kandungan yang terdapat pada daun salam yaitu minyak atsiri yang tidak disukai oleh serangga..

a. Sebaiknya pemerintah mempertimbangkan untuk menggunakan insektisida alami dalam pengendalian vektor karna ramah lingkungan, residunya mudah hilang dan aman bagi manusia serta hewan lainnya .

\section{DAFTAR PUSTAKA}

Aang.2012.Periplata americana.(online) http://aangefound.com/2012/05/ Periplata-americana.html. Diakses 29 januari 2018

Abidatun I,M, W.S, Utami, L, Ameliana.2013.Efektifitas Biolarvasida Minyak Daun Jeruk Purut (Citrus hystric) terhadap Larva Instar III Nyamuk Aedes Aegypti. Artikel Penelitian Mahasiswa.Jember.Fakultas Kedokteran Universitas Jember. (online) http://journal.unnes.ac.id. Diakses 8 januari 2018.

Amin, Ika Dina, Retno Hestiningsih, and Sri Yuliawati. "Pengujian Daun Jeruk Purut (Citrus Hystrix) Sebagai Zat Penolak Alami Bagi Kecoa Jerman (Blatella Germanica) Dewasa Di Laboratorium." Jurnal Kesehatan Masyarakat (e-Journal) 4.1 (2016): 127-133. (online) file:///D:/KECO/1166523130-1-SM.pdf. Diakses 01 januari 2018

Anonim.2017.Kecoa Amerika (Periplanetta americana). (online) http://www.fapeonline.com/?=316 . Diakses 17 januari 2018.

Anonim.2011. Kecoa Jerman . (online) http://upikke.staff.ipb.ac.id/2011/05/11/lipas-atau-kecoak-jermanblatella-germanica/. Diakses 15 juli 2018.

Anonim.2011. Kecoa Oriental. (online) https://bugguide.net/node/view/321762. Diakses 15 juli 2018.

Anonim.2011. Supella langipalpa. (online) http://upikke.staff.ipb.ac.id/2011/05/16/lipas-atau-kecoakberpita-coklat-supella-longipalpa/. Diakses 15 juli 2018.

Anonim.2014.Morfologi Kecoa Amerika.(online) http://kecoaislife.wordpress.com/authorkecoaislife/ . Diakses 11 januari 2018.

Anonim.2015.Siklus Hidup Kecoa Amerika. (online) www.extention.umn.edu.com . Diakses 11 januari 2018.

Anonim.2014.Jeruk Purut.(online) http://kesehatandia.blogspot.co.id/2014/11/manfaat-jeruk-purutuntuk-kesehatan-dan.html?m=1. Diakses 10 januari 2018.

Anonim.2016.Daun Salam.(online). http://ahmadjr.com/16-manfaat-yang-teerkandung-dari-daunsalam/.Diakses 10 januari 2018.

Baskoro, A. D., Sudjari, Ahmed R. F., dan Ridwan R. 2013. Uji Potensi Ekstrak Kulit Jeruk Nipis (Citrus aurantiifolia) Sebagai Pengusir (Repellent) Kecoak Periplaneta americana. (online) 
Jurnal Sulolipu : Media Komunikasi Sivitas Akademika dan Masyarakat

Vol. 18 No 22018

e-issn : 2622-6960, p-issn: 0854-624X

http://old.fk.ub.ac.id/artikel/id/filedownload/kedokteran/ahmed\%20ram

\%20firdause\%20b\%20ridwan\%20_0710714002_.pdf. Diakses pada 7 juli 2018.

Dalimartha, S.2000. Salam (Syzygium polyanthum [Wight] Walp.) Atlas Tumbuhan Obat Indonesia 2 : 161-165. Diakses 9 januari 2018

Departemen Kesehatan Republik Indonesia.2002.Pedoman Pengendalian Kecoa Di Rumah Sakit.Jakarta : Departemen Kesehatan RI.

Eki Septisni Putri,2017, Efektifitas Daun Citrus hystrix dan Daun Syzygium polyanthum Sebagai Zat Penolak Alami Periplaneta americana (L.),1 (4) : 154-162. (online) file:///D:/KECO/16309Article\%20Text-36858-1-10-20171101-1.pdf . Diakses 01 januari 2018.

Hartati, S. Y. 2012. Prospek Pengembangan Minyak Atsiri Sebagai Pestisida Nabati. (online) http://www.google.com/url?q=http://perkebunan.litbang.deptan.go.id/wp. Diakses 08 juli 2018.

Herma Amelian, dan Idham Sakti Harahap.2010. Preferensi Kecoa Periplaneta americana (L.) (Blattaria: Blattidae) terhadap Berbagai Kombinasi Umpan,7 (2) : 67-77. (online) file:///D:/KECO/91-262-1PB.pdf . Diakses 01 januari 2018.

Khasanah, Lia Umi, et al. 2015. Pengaruh Perlakuan Pendahuluan Terhadap Karakteristik Mutu Minyak Atsiri Daun Jeruk Purut (Citrushystrix). (Online) http://jatp.ift.or.id/index.php/jatp/article/view/98. Diakses 29 Mei 2018.

Koswara, S. 2009. Menyuling dan Menepungkan Minyak Asiri Daun Jeruk Purut. (online) http://www.ebookpangan. com/ARTIKEL/MENYULING\%20DAN \%20MENEPUNGKAN\%20MINYAK\%2 0ASIRI.pdf [diakses tanggal 11 Januari 2018.

Meita Mahardianti,2014, Uji Daun Salam (Syzygium polyanthum) Sebagai Zat Penolak Alami Bagi Kecoa Amerika (Periplaneta americana) Dewasa,Lampung : Fakultas Matematika Dan IImu Pengetahuan Alam Universitas Lampung. (online) file:///D:/KECO/123dok_uji_daun_salam_syzygium_polyanthum_sebagai_zat_penolak_alami_b agi_kecoa_amerika_periplaneta_ameri.pdf. Diakses 03 januari 2018.

Mora, Enda, Musyirna Rahmah Nasution, and Pinni Maya Nita. "Isolasi Metabolik Sekunder Dan Uji Aktifitas Ekstrak Larvasida Etanol Daun Sirsak (Annona muricata Linn) Terhadap Larva Nyamuk Aedes aegypti." SCIENTIA Jurnal Farmasi dan Kesehatan 4.1(2016):17-21.(online) file://C:/Users/DELL/Downloads/74-164-1-SM.pdf . Diakses 04 Januari 2018.

Naria.2005. Insektisida Nabati Untuk Rumah Tangga.Departemen Kesehatan Lingkungan.Fakultas Kesehatan Masyarakat.Universitas Sumatera, Medan. (online) http://journal.poltekkes-mks.ac.id . Diakses 06 Januari 2018

Oktarina,Rini.2002.Efektifitas Serbuk Biji Lada (Piper ningrum) Sebagai Repellent Alami Kecoa (Periplaneta americana).(online) http://

Republik Indonesia.2017.Keputusan Menteri Kesehatan Republik Indonesia Nomor 50 Tahun 2017 tentang Standar Baku Mutu Kesehatan Lingkungan dan Persyaratan Kesehatan Untuk Vektor dan Binatang Pembawa Penyakit Serta pengendaliannya.(online) file:///D:/KECO/PMK_No._50_ttg_Standar_Baku_mutu_KESLING_dan_Persyaratan_Kesehatan _Vektor_.pdf.Diakses 02 januari 2018.

Sarmilah.2016.Kemampuan Bubuk Mentimun Dan Daun Salam Untuk Mematikan Kecoa.Makassar:Politeknik Kesehatan Makassar Jurusan Kesehatan Lingkungan.

Sudjari, Agustina T. E., dan Robby H. 2006. Efek Repellent Ekstrak Daun Salam (Eugenia polyantha Wight) Terhadap Nyamuk Culex sp. (online) http://elibrary.ub.ac.id Diakses pada 7 juli 2018 
Jurnal Sulolipu : Media Komunikasi Sivitas Akademika dan Masyarakat Vol. 18 No 22018

e-issn : 2622-6960, p-issn: 0854-624X

Yuliani, Titiek Siti, et al. 2011.Pestisida Rumah Tangga Untuk Pemukiman Hama Pemukiman PadaRumah Tangga. Jurnal Pengelolaan Sumberdaya Alam dan Lingkungan (Journal of Natural Resources and Environmental Management) 1.2(2011):73.(online) http://mail.student.ipb.ac.id/index.php/jpsl/article/view/10703 . Diakses 05 Januari 2018. 